\title{
PERENCANAAN KEBIJAKAN PERSEDIAAN KATEGORI FLOOR TILE DENGAN MODEL P DAN JOINT REPLENISHMENT UNTUK MEMINIMASI TOTAL BIAYA PERSEDIAAN PADA CENTRAL WAREHOUSE PT.XYZ KARAWANG
}

\author{
PLANNING POLICY INVENTORY FLOOR TILE \\ CATEGORIES USING P MODEL AND JOINT \\ REPLENISHMENT TO MINIMIZE TOTAL COST OF \\ INVENTORY IN CENTRAL WAREHOUSE PT.XYZ \\ KARAWANG
}

\author{
${ }^{1}$ Amrina Rosyada, ${ }^{2}$ Muhammad Iqbal, ${ }^{3}$ Murni Dwi Astuti \\ 1,2,3 Program Studi Teknik Industri, Fakultas Rekayasa Industri, Telkom University \\ 1amrinarosyada@telkomuniversity.ac.id, ${ }^{2}$ muhiqbal@telkomuniversity.ac.id, ${ }^{3}$ murnidwiastuti@telkomuniversity.ac.id
}

\begin{abstract}
Abstrak-PT. XYZ Karawang merupakan distributor tunggal untuk produkproduk dari PT. ABC. Lokasi penyimpanan yang terletak di Karawang ini mendistribusikan banyak jenis keramik. Sebagai distributor tunggal, PT. XYZ harus mendistribusikan keramik baik ke 19 cabang di seluruh Indonesia maupun langsung ke end customer. Terdapat dua jenis keramik, yaitu floor tile dan wall tile. Dalam menentukan kebijakan persediaan, PT. XYZ belum menggunakan perhitungan baku. Hal ini membuat PT. XYZ melakukan pembelian keramik berlebih sehingga menyebabkan overstock pada persediaan keramik. Kondisi ini membuat PT. XYZ harus menanggung tingginya biaya total persediaan di gudang. Penelitian ini dilakukan untuk memberikan usulan kebijakan persediaan keramik jenis floor tile 40x40 untuk meminimasi total biaya persediaan. Kebijakan persediaan yang diusulkan merupakan hasil perhitungan menggunakan metode joint replenishment dan Model P, dimana pemesanan keramik dilakukan secara bersamaan selama interval waktu tertentu. Hasil dari kebijakan ini berupan interval review, reorder point, tingkat persediaan maksimum, dan safety stock. Hasil perhitungan kebijakan persediaan untuk floor tile 40x40 memberikan penghematan total biaya persediaan sebesar $45.80 \%$ atau sebesar Rp.473.495.683. Dari hasil tersebut diperlukan penerapan kebijakan keramik di PT. XYZ Karawang agar dapat menurunkan total biaya persediaan.
\end{abstract}

Kata kunci: Overstock, Inventori, Joint replenishment, Model P

Abstract - PT. XYZ Karawang is a single distributor for the products from PT. ABC. The warehouse located in Karawang and distributes several types of tile. As a single distributor, PT. XYZ should distribute the tile not only to 19 branches in Indonesia, but

$\begin{array}{ll}\text { Sejarah artikel } & \\ \text { Diterima redaksi: } & : 14 \text { Juni } 2017 \\ \text { Revisi akhir } & : 25 \text { Juli } 2017 \\ \text { Diterbitkan online } & : 12 \text { Desember } 2017\end{array}$

also to end customer. There are two types of tile, floor tile and wall tile. In determining inventory policies, PT. XYZ has not using standard calculation. It makes PT. XYZ purchases excess the tile which causing overstock. This condition makes the total inventory cost in PT.XYZ become very high. Therefore, this study aims to provide inventory policies of floor tile type $40 \times 40$ so that the total inventory cost can be minimized. The proposed inventory policies is the result from the calculation using Joint replenishment and Pmodel, where the tile is purchased together over a certain interval of time. The results of this research are inventory policies variables i.e. interval review, reorder point, maximum inventory level and safety stock. Based on the result, the calculation of inventory policies for floor tile $40 \times 40$ reduces the total inventory cost of $45.80 \%$ or Rp473.495.683. From the result, the implementation of inventory policies in PT.XYZ is required, so that the total inventory cost can be minimized.

Keywords - Overstock, Inventory, Joint replenishment, P Model

\section{PENDAHULUAN}

Pertumbuhan ekonomi Indonesia mengalami peningkatan yang signifikan beberapa tahun terakhir ini, yaitu sekitar 5,18\% dibandingkan tahun lalu [1]. Pertumbuhan ekonomi diperkirakan akan terus berlanjut untuk tahun selanjutnya. Hal ini dipengaruhi oleh fokus Pemerintah dalam melakukan Pembangunan infrastruktur berupa sektor properti hunian. Jumlah permintaan terhadap hunian ini diikuti dengan banyaknya jumlah permintaan terhadap keramik. Seiring dengan kemajuan zaman dan teknologi, keramik tidak hanya berfungsi sebagai penutup lantai. Keramik bisa difungsikan sebagai bahan penutup dinding dan bahan tempelan penghias elemen interior rumah. 
Salah satu aktivitas yang mendukung lancarnya rantai pasok tersebut adalah persediaan. Persediaan atau biasa disebut inventory merupakan suatu sumber yang menganggur tetapi mempunyai nilai yang ekonomis [2]. Persediaan menjadi unsur penting dalam perusahaan untuk memenuhi permintaan sehingga akan memberikan keuntungan bagi perusahaan.

PT.XYZ Karawang merupakan distributor tunggal untuk produk-produk dari PT. ABC. Lokasi penyimpanan yang terletak di Karawang ini mendistribusikan banyak jenis keramik. Terdapat dua jenis keramik, yaitu keramik untuk di lantai (floor tile ) dan keramik untuk di dinding (floor tile). Perusahaan ini telah berkespansi memasarkan produknya baik dalam maupun luar negeri. Terdapat 19 cabang yang tersebar di kota-kota strategis seluruh Indonesia yang dijadikan sebagai jaringan distribusinya. PT. XYZ harus dapat mendistribusikan produk sesuai dengan permintaan. Jumlah persediaan yang terlalu banyak mengakibatkan barang menumpuk di gudang dan terjadi pemborosan terhadap biaya simpan, namun jika terlalu sedikit dapat berdampak pada hilangnya keuntungan yang bisa perusahaan dapatkan. Saat ini manajemen persediaan keramik di PT.XYZ terbilang belum baik. Hal ini dikarenakan belum terdapatnya kebijakan dalam menentukan reorder point yang menimbulkan pemesanan berlebih dan terdapatnya minimum order quantity dari pihak supplier. Perusahaan memiliki kebijakan masingmasing terhadap persediaan produk floor tile maupun floor tile. Grafik yang menunjukkan jumlah persediaan produk floor tile dan floor tile terhadap kebijakan persediaannya selama periode Januari hingga Desember 2015 dapat dilihat berdasarkan Gambar 1 dan Gambar 2. Dapat dilihat bahwa produk floor tile 40x40 mengalami overstock. Keadaan manajemen persediaan dapat dinilai berdasarkan nilai Inventory Turnover [3]. Nilai rasio inventory turnover menunjukkan seberapa cepat barang didalam gudang berputar dan memperlihatkan ukuran efektivitas manajemen inventori yang berlaku. Nilai inventory turnover untuk produk floor tile 40x40 dapat dilihat melalui Gambar 3.

Nilai standar ITO untuk produk floor tile 40x40 yaitu 0,11. Berdasarkan Gambar 3, produk floor tile ukuran 40x40 memiliki nilai ITO yang rendah bagi perusahaan untuk beberapa bulan. Hal ini semakin memperkuat bahwa manajemen persediaan PT.XYZ harus diperbaiki [3]. Persediaan merupakan suatu sumber yang menganggur tetapi mempunyai nilai yang ekonomis .Melihat tingginya inventori pada produk floor tile 40x40, maka penelitian ini difokuskan pada produk kategori floor tile 40x40. Masalah overstock dapat meningkatkan ongkos penyimpanan dan menumpuknya barang di gudang PT XYZ. Jumlah inventory yang terlalu banyak menyebabkan besarnya biaya yang harus ditanggung perusahaan. Berdasarkan permasalahan tersebut, maka tujuan penelitian ini adalah untuk menentukan kebijakan persediaan floor tile 40x40 untuk mengatasi permasalahan overstock.

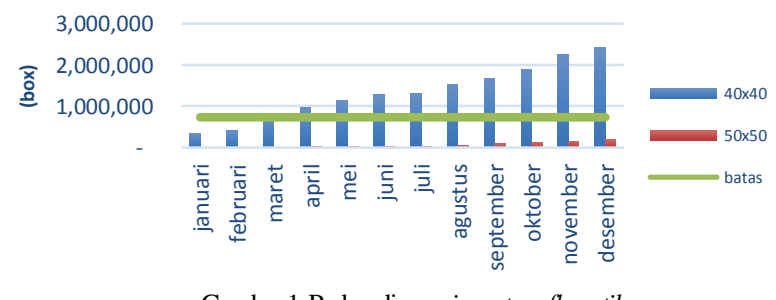

Gambar 1 Perbandingan inventory floor tile

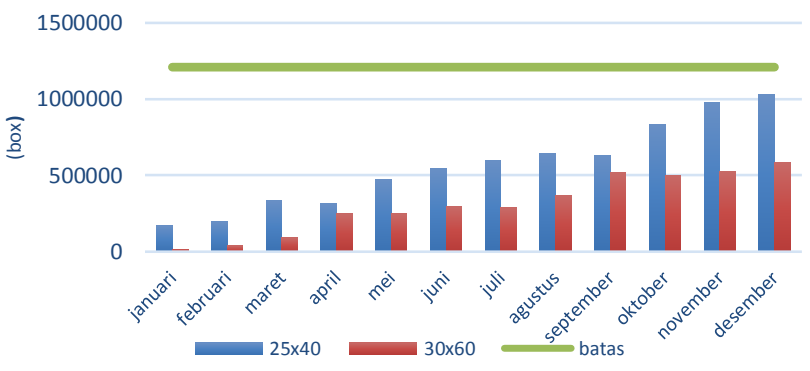

Gambar 2 Perbandingan inventory wall tile

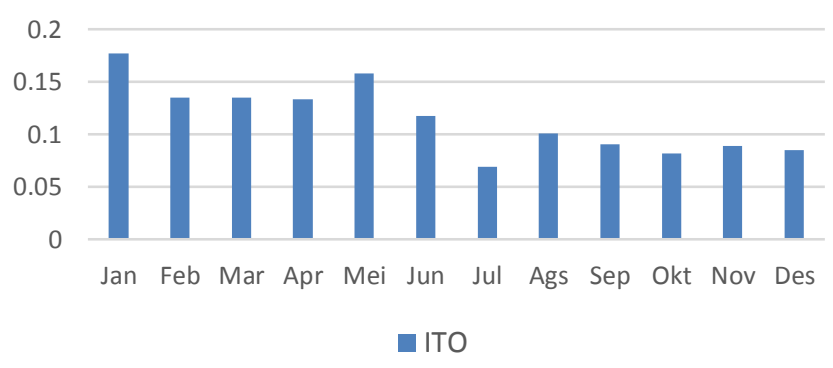

Gambar 3 ITO Floor tile 40x40

Metode Joint replenishment digunakan karena sesuai dengan karakteristik perusahaannya yaitu hanya memiliki satu supplier [4]. Adapun asumsi pada metode ini yaitu lead time konstan, semua produk dipesan pada supplier yang sama dan dipesan dalam waktu yang sama [5]. Selain itu, distribusi produk dilakukan dengan transportasi yang sama [6]. Pengendalian persediaan ini memiliki tingkat yang lebih tinggi untuk diterapkan dalam kehidupan nyata bila dibandingkan dengan pemesanan tunggal [7]. Dengan dilakukannya pemesanan secara bersama ini membuat syarat minimum order dapat terpenuhi. Kebijakan inventori terkait dengan berapa jumlah barang yang akan dipesan, kapan saat pemesanan dilakukan, serta berapa jumlah inventori pengamannya [8]. Kebijakan ini dapat diperoleh melalui pengendalian probabilistik model P. Karakteristik model P yaitu pemesanan dilakukan sesuai dengan waktu interval nya dan jumlah pemesanan dilakukan hingga jumlah persediaan mencapai titik maksimum level nya [9]. Inventori level ditentukan untuk memenuhi permintaan hingga pemesanan berikutnya pada interval waktu yang tetap [10]. Oleh karena itu, penelitian ini membahas tentang pengendalian persediaan produk floor tile 40x40 dengan tujuan meminimasi total biaya persediaan dengan menggunakan metode Joint replenishment dan model P.

\section{HASIL DAN ANALISIS}

A. Perhitungan biaya eksisting

Beberapa data dan perhitungan biaya saat ini pada penelitian ini dicontohkan pada SKU Z21KAA486ASBR7D1 seperti :

a. Demand: data permintaan pada penelitian ini merupakan data selama 12 bulan yang ditunjukkan pada Tabel I.

b. Uji Distribusi: uji distribusi dilakukan terhadap data permintaan melalui Kolmogorv Smirnov. Dengan menggunakan taraf kepercayaan 95\%, SKU Z21KAA486ASBR7D1 dinyatakan berdistribusi normal. 
c. Lead time: pada SKU Z21KAA486ASBR7D1 memiliki lead time sebesar 1 hari.

d. Biaya penyimpanan: dengan beberapa komponen biaya simpan yang ada, maka didapat bahwa biaya simpan per unit adalah Rp 64.09 setiap bulannya. Tabel II merupakan biaya simpan untuk SKU Z21KAA486ASBR7D1 selama 12 bulan.

e. Biaya Pesan : biaya pesan terdiri atas dua komponen, yaitu biaya pesan minor dan mayor. Dalam waktu 12 bulan, SKU Z21KAA486ASBR7D1 memiliki biaya pesan minor sebesar Rp17.553. Biaya pesan mayor untuk seluruh pemesanan dapat dilihat pada Tabel III

f. Biaya kekurangan: biaya kekurangan merupakan biaya yang dikeluarkan oleh perusahaan apabila produk mengalami kekurangan. Perhitungan dilakukan dengan mengalikan antara biaya kekurangan dengan banyaknya barang yang mengalami kekurangan. Pada SKU Z21KAA486ASBR7D1, tidak terjadi kekurangan, sehingga biaya kekurangan yaitu Rp 0

g. Total biaya persediaan aktual: keseluruhan biaya pada kondisi saat ini perusahaan ditunjukkan pada Tabel IV.

\begin{tabular}{cc} 
TABELI & \\
& DEMAND \\
\hline Bulan & Demand \\
\hline Januari & 0 \\
Februari & 0 \\
Maret & 0 \\
April & 0 \\
Mei & 0 \\
Juni & 265 \\
Juli & 350 \\
Agustus & 950 \\
September & 200 \\
Oktober & 1235 \\
November & 651 \\
Desember & 368 \\
\hline
\end{tabular}

\begin{tabular}{|c|c|c|c|c|}
\hline \multicolumn{5}{|c|}{$\begin{array}{c}\text { TABELII } \\
\text { BIAYA SIMPAN }\end{array}$} \\
\hline Bulan & $\begin{array}{l}\text { Jumlah unit } \\
\text { yang } \\
\text { disimpan } \\
\text { (m) }\end{array}$ & $\begin{array}{c}\text { Biaya } \\
\text { Simpan/unit/ } \\
\text { bulan (h) }\end{array}$ & \multicolumn{2}{|c|}{$\begin{array}{l}\text { Total Biaya Simpan } \\
\quad(\mathrm{Os}=\mathrm{h} \times \mathrm{m})\end{array}$} \\
\hline Jan & 0 & Rp. 64.09 & $\mathrm{Rp}$ & - \\
\hline Feb & 0 & Rp. 64.09 & $\mathrm{Rp}$ & - \\
\hline Mar & 0 & Rp. 64.09 & $\mathrm{Rp}$ & - \\
\hline Apr & 0 & Rp. 64.09 & $\mathrm{Rp}$ & - \\
\hline Mei & 0 & Rp. 64.09 & $\mathrm{Rp}$ & - \\
\hline Jun & 35 & Rp. 64.09 & $\mathrm{Rp}$ & $2,243.02$ \\
\hline Jul & 35 & Rp. 64.09 & $\mathrm{Rp}$ & $2,243.02$ \\
\hline Ags & 96 & Rp. 64.09 & $\mathrm{Rp}$ & $6,152.29$ \\
\hline Sep & 13089 & Rp. 64.09 & $\mathrm{Rp}$ & $838,826.06$ \\
\hline Okt & 11854 & Rp. 64.09 & $\mathrm{Rp}$ & $759,679.44$ \\
\hline Nov & 11309 & Rp. 64.09 & $\mathrm{Rp}$ & $724,752.38$ \\
\hline Des & 11109 & Rp. 64.09 & $\mathrm{Rp}$ & $711,935.12$ \\
\hline \multicolumn{3}{|c|}{ Total Biaya Simpan } & \multicolumn{2}{|c|}{$\operatorname{Rp} 3,045,831.33$} \\
\hline
\end{tabular}

TABELIII

PERHITUNGAN BIAYAPESANMAYOR

\begin{tabular}{ccc}
\hline $\begin{array}{c}\text { Frekuensi Pesan } \\
\text { (f) }\end{array}$ & $\begin{array}{c}\text { Biaya sekali pesan } \\
\text { (A) }\end{array}$ & $\begin{array}{c}\text { Total biaya Pesan } \\
\text { (f x A) }\end{array}$ \\
\hline 295 & Rp. 36,050 & Rp. 10,634,750 \\
\hline
\end{tabular}

TABELIV

TOTAL BIAYA PERSEDIAAN SAAT INI

\begin{tabular}{|c|c|c|c|}
\hline $\begin{array}{c}\text { Ongkos Simpan } \\
\text { (Os) }\end{array}$ & $\begin{array}{l}\text { Ongkos } \\
\text { Pesan } \\
(\mathrm{Op}) \\
\end{array}$ & $\begin{array}{c}\text { Ongkos } \\
\text { Kekurangan } \\
(\mathrm{Cu}) \\
\end{array}$ & $\begin{array}{l}\text { Total Ongkos } \\
(\mathrm{Os}+\mathrm{Op}+\mathrm{Cu})\end{array}$ \\
\hline $3,045,831$ & Rp17.553 & $\mathrm{Rp}-$ & $\mathrm{Rp} 3,063,384$ \\
\hline
\end{tabular}

B. Kebijakan persediaan usulan

Kebijakan persediaan usulan dilakukan dengan dua tahap,yaitu menghitung waktu pemesanan dengan joint replenishment dan dilanjutkan dengan perhitungan dengan model $\mathrm{P}$ Hadley-within untuk kasus lost sales

\section{Perhitungan waktu pemesanan joint replenishment}

Tahap 1 dilakukan perhitungan untuk menentukan nilai Ti* tiap SKU. Pada perhitungan ini dicontohkan perhitungan SKU Z21KAA486ASBR7D1 dengan informasi-informasi seperti pada Tabel V. Pada tahap 2, setelah didapatkan nilai Ti* untuk seluruh SKU, identifikasi nilai Ti* terkecil. SKU yang memiliki Ti* paling kecil dinotasikan sebagai item 1 . Ti* merupakan nilai interval review untuk single item Urutan nilai $\mathrm{Ti}^{*}$ pada nilai yang paling kecil adalah SKU Z21KIA481HETA2E1. Maka selanjutnya perhitungan akan dilanjutkan dengan menghitung SKU ini sebagai contoh dengan nilai $\mathrm{k}=1$. Berikut merupakan contoh perhitungan dalam menentukan nilai $\mathrm{T}$ dengan menggunakan $\mathrm{ki}=1$. Pada tahap 3 dilakukan penentuan nilai $\mathrm{T}$ dengan menggunakan $\mathrm{ki}=1$. Untuk $\mathrm{Ti} *$ terkecil yaitu $\mathrm{SKU}$ Z21KIA481HETA2E1 dengan nilai Disebesar 12.776 unit, L sebanyak 0.033 unit, $\sigma$ i senilai 6.611,3, h sebesar Rp 64,09, Cu sebesar Rp 7300, A sebesar Rp36,050.00, dan ai sebesar Rp 3.511

TABEL V

DATA PERHITUNGAN JOINT REPLENISHMENT

\begin{tabular}{|c|c|c|}
\hline Variabel & Notasi & Nilai \\
\hline Biaya pesan minor & $\overline{\mathrm{ai}}$ & $\operatorname{Rp} 3.511 /$ pesan \\
\hline Biaya pesan mayor & A & Rp 36.050/ pesan \\
\hline Biaya simpan & hi & Rp 64.09/ unit/ bulan \\
\hline Rata-rata demand & Di & 335 \\
\hline Deviasi normal & $\mathrm{Zi}$ & 1.64 \\
\hline Standar deviasi & $\sigma \mathrm{i}$ & 412.7 \\
\hline Lead time & $\mathrm{Li}$ & 0.033 bulan \\
\hline
\end{tabular}

$T 01=\sqrt{\frac{2 a i}{h i D i}}=0.572$ bulan

$T i *=\sqrt{\frac{2 a i}{h i\left(D i+\left(\frac{z i \sigma \mathrm{i}}{\sqrt{T o i+L i}}\right)\right)}}=0.302$ bulan

$T 01=\sqrt{\frac{2(A+a i)}{h i D i}}=0.31$ bulan

$T i=\sqrt{\frac{2(A+a i)}{h i\left(D i+\left(\frac{z i \sigma \mathrm{i}}{\sqrt{T o i+L i}}\right)\right)}}=0.198$ bulan

Pada tahap 4, nilai k untuk SKU lainnya ditentukan. Nilai k bernilai integer dan dapat memenuhi persamaan (5). Selanjutnya, pada tahap 5, dilakukan perhitungan untuk menentukan nilai $\mathrm{T}$ 
dimana nilai ini merupakan interval review untuk seluruh SKU. Perhitungan menggunakan persamaan (6) dan (7). Setelah itu, pada tahap 6 dilakukan perhitungan total biaya persediaan dengan menggunakan persamaan (8). Berdasarkan hasil perhitungan, diperoleh nilai TC sebesar Rp. 8.050.079,90

$$
\sqrt{q(q-1)} \leq \frac{T i *}{T} \leq \sqrt{q(q+1)}
$$

$T 01=\sqrt{\frac{2\left(A+\sum_{i=1}^{n} \frac{a i}{k i}\right)}{\sum_{i=1}^{n} h i k i D i}}=0.256587325$ bulan

$T=\sqrt{\frac{2\left(A+\sum_{i=1 \frac{a i}{k i}}^{n}\right)}{\sum_{i=1}^{n} h i k i\left(D i+\left(\frac{z i \sigma \mathrm{i}}{\sqrt{T o i+L i}}\right)\right)}}=0.14$ bulan

$$
\begin{aligned}
T C=\frac{A}{T}+\frac{a_{i}}{T}+\frac{\sum_{i=2}^{n} a_{i} / k_{i}}{T_{1}}+\frac{D_{1} T h_{1}}{2}+z_{1} \sigma_{1} h_{1} \sqrt{T+L_{1}} \\
+\sum_{i=2}^{n}\left[\frac{D_{i} k_{i} T h_{i}}{2}+z_{i} \sigma_{i} h_{i} \sqrt{k_{i} T+L_{i}}\right]
\end{aligned}
$$

Tahap berikutnya adalah dengan mengulangi langkah 4 dan 5 sehingga biaya total persediaan gabungan yang dihasilkan pada setiap iterasi menghasilkan selisih biaya yang nilainya sama. Tabel V merupakan perbandingan total biaya tiap iterasi. Pada Tabel V. terlihat bahwa iterasi dilakukan hingga iterasi ke-16 dimana dari iterasi 9 hingga iterasi ini telah menghasilkan total biaya yang sama. Maka perhitungan selanjutnya adalah berdasarkan iterasi ke-9, dimana nilai $\mathrm{T}$ yang didapat adalah 0.155 bulan.

2. Perhitungan dengan menggunakan model P Hadley-within

Berikut merupakan perhitungan dengan menggunakan model $\mathrm{P}$ Hadley-within untuk kasus lost sales untuk SKU Z21KIA481HETA2E1 [9].

\begin{tabular}{lcc}
\hline \multicolumn{1}{c}{ Variabel } & Notasi & Nilai \\
\hline Jumlah demand & $\mathrm{D}$ & 153.306 unit \\
Standar deviasi demand & $\sigma$ & $6.611,3$ \\
Biaya simpan & $\mathrm{hi}$ & $\mathrm{Rp} 64.09 /$ unit/ bulan \\
Biaya pesan & $\mathrm{A}+\mathrm{ai}$ & $\mathrm{Rp} \mathrm{39.561}$ \\
Biaya kekurangan & $\mathrm{Cu}$ & $\mathrm{Rp} \mathrm{5.080/} \mathrm{unit}$ \\
Lead time & $\mathrm{Li}$ & $0.033(1$ hari) \\
Interval review & $\mathrm{T}$ & 0.155 bulan \\
\hline
\end{tabular}

Pada tahap 1 dilakukan perhitungan reorder point. Reorder point dihitung dengan mengalikan hasil nilai $\mathrm{T}$ atau interval review dengan menggunakan metode Joint replenishment dengan konstanta $\mathrm{k}$. Kemudian, berdasarkan nilai $\mathrm{R}$ yang diperoleh, selanjutnya yaitu dilakukan perhitungan untuk mendapatkan nilai $\alpha$, yaitu kemungkinan kekurangan persediaan untuk setiap SKU dengan persamaan (10)

$$
\begin{aligned}
& \mathrm{R}=\mathrm{ki} \times \mathrm{T}=0.155 \text { bulan } / 4 \text { hari } \\
& \alpha=\frac{R \times h}{(R \times h)+C u}=0.0019
\end{aligned}
$$

\begin{tabular}{|c|c|}
\hline Iterasi & Total Biaya \\
\hline Iterasi 1 & Rp 8,050,079.90 \\
\hline Iterasi 2 & Rp 8,112,635.83 \\
\hline Iterasi 3 & Rp 8,129,332.84 \\
\hline Iterasi 4 & $\operatorname{Rp} 8,167,170.49$ \\
\hline Iterasi 5 & Rp 8,185,599.17 \\
\hline Iterasi 6 & Rp 8,225,266.38 \\
\hline Iterasi 7 & Rp 8,225,266.38 \\
\hline Iterasi 8 & Rp 8,254,933.28 \\
\hline Iterasi 9 & $\operatorname{Rp} 8,280,451.14$ \\
\hline Iterasi 10 & Rp 8,280,451.14 \\
\hline Iterasi 11 & Rp 8,280,451.14 \\
\hline Iterasi 12 & $\operatorname{Rp} 8,280,451.14$ \\
\hline Iterasi 13 & Rp 8,280,451.14 \\
\hline Iterasi 14 & Rp 8,280,451.14 \\
\hline Iterasi 15 & Rp 8,280,451.14 \\
\hline Iterasi 16 & Rp 8,280,451.14 \\
\hline
\end{tabular}

TABEL VI

PERBANDINGANTOTAL COST

Pada tahap 3, dilakukan perhitungan terhadap nilai maksimum inventori level. Melalui tabel normal dapat dilihat bahwa untuk $\alpha=$ 0.0019 didapatkan nilai yaitu 2.9. Sedangkan untuk nilai $\mathrm{N}$ atau ekspektasi terjadi kekurangan barang dapat dihitung dengan menggunakan persamaan (12)

$S=D R+D L+Z_{\alpha} \sigma \sqrt{R+L}=37120$ unit

$N=\sigma \sqrt{R+L}\left[f\left(Z_{\alpha}\right)-\left(Z_{\alpha}\right) \Psi\left(Z_{\alpha}\right)\right]$

Dengan nilai $\left(Z_{\alpha}\right)=2.9$, maka $f\left(Z_{\alpha}\right)=0.0059$ dan $\Psi\left(Z_{\alpha}\right)=0.0005$, sehingga $\mathrm{N}=13$ unit. Pada tahap berikutnya dilakukan perhitungan terhadap safety stock dengan menggunakan persamaan (13)

$s s=Z_{\alpha} \sigma \sqrt{R+L}=8312$ unit

Berikutnya pada tahap 5 dilakukan perhitungan terhadap ongkos total persediaan. Setelah melakukan perhitungan kebijakan untuk semua SKU, maka dihitung biaya total persediaan usulan. Selanjutnya akan dijelaskan perhitungan biaya pada SKU Z21KIA481HETA2E1 [2] :

a. Biaya Simpan (Os)

$O s_{1}=h\left(S-D L+\frac{D R}{2}+N\right)$

$O s_{1}=R p 2,811,587 \quad /$ bulan

$O s_{1}=R p 33,739,042 \quad /$ tahun

Total $O s=\sum_{i=1}^{n} O s i$

$$
\begin{aligned}
& =R p 35,172,076 / \text { bulan } \\
& =\operatorname{Rp~422,064,917/tahun~}
\end{aligned}
$$

b. Biaya pesan (Op)

Biaya pesan terdiri atas biaya pesan minor dan biaya pesan mayor. Biaya pesan minor menunjukkan biaya pesan per SKU 
dan biaya mayor menunjukkan biaya pesan yang tidak bergantung pada banyaknya SKU yang dipesan untuk setiap kali pesan.

Op Minor $=\frac{a i}{R}$

Op Minor $=R p 22,710 /$ bulan

op Minor $=R p 272,525 /$ tahun

Sehingga diperoleh total biaya pesan sebagai berikut:

Total Op Minor $=\sum_{i=1}^{n} O p i$

$$
\begin{aligned}
& =R p 2,134,783 / \text { bulan } \\
& =R p 25,617,391 / \text { tahun }
\end{aligned}
$$

Selanjutnya biaya pesan mayor dapat dihitung sebagai berikut :

$$
\begin{aligned}
& \text { op Mayor }=\frac{A}{R} \\
& \text { Op Mayor }=R p 233,212 / \text { bulan } \\
& \text { op Mayor }=R p 2,798,542 / \text { tahun }
\end{aligned}
$$

Maka, biaya pesan keseluruhan untuk 1 tahun menjadi:

$O p=O p$ Minor + Op Mayor

$O p=R p 25,617,391+R p 2,798,542$

$O p=R p 28,415,932 /$ tahun

c. Biaya Kekurangan (Ok)

$O k_{1}=\frac{C u \times N}{R}$

$O k_{1}=\operatorname{Rp} 427,221 /$ bulan

$O k_{1}=\mathrm{Rp} 5,126,648.57 /$ tahun

Sehingga dapat diperoleh total biaya kekurangan sebagai berikut:

$$
\text { Total } \begin{aligned}
\text { Ok } & =\sum_{i=1}^{n} \text { Oki } \\
& =R p 9,145,396 / \text { bulan } \\
& =R p 109,744,747 / \text { tahun }
\end{aligned}
$$

d. Total ongkos persediaan :

$\mathrm{OT}=\mathrm{Os}+\mathrm{Op}+\mathrm{Ok}$

OT $=$ Rp 422,064,917 + Rp28,415,932+ Rp109,744,747

OT $=$ Rp560,225,597 / tahun

Berdasarkan perhitungan yang telah dilakukan, maka dapat diketahui bahwa secara keseluruhan, kondisi usulan mengalami penghematan biaya sekitar $45.80 \%$ dengan rincian sebagai berikut:

a. Perbandingan Total Biaya Simpan Kondisi Saat ini dan Usulan

b. Total biaya simpan pada kondisi saat ini adalah sebesar Rp1,024,744,692 , sedangkan biaya simpan yang dihasilkan dari kondisi usulan yaitu Rp422,064,917. Hal ini menunjukkan terjadi penghematan sekitar $58.81 \%$ atau sebesar Rp602,679,774. Penghematan ini terjadi dikarenakan jumlah produk yang harus dipesan lebih sedikit dari kondisi saat ini. Sebagaimana yang telah dijelaskan sebelumnya, jumlah produk yang harus dipesan didapatkan dari selisih antara jumlah maksimum inventori level dan jumlah persediaan produk saat itu di gudang. Maka dari itu, besarnya jumlah maksimum inventori level akan mempengaruhi jumlah barang yang disimpan yang mengakibatkan besarnya biaya simpan yang dikeluarkan.

c. Perbandingan Total Biaya Pesan Kondisi Saat ini dan Usulan d. Total biaya pesan kondisi saat ini adalah sebesar Rp8,976,588, sedangkan pada biaya pesan kondisi usulan adalah sebesar Rp28,415,932. Hal ini menunjukkan terjadinya kenaikan total biaya pesan sebesar Rp19,439,344. Hal ini dikarenakan frekuensi pemesanan lebih banyak yaitu setiap 4 hari untuk masing-masing SKU, sehingga membuat biaya pesan mengalami kenaikan. Artinya, perusahaan melakukan pemesanan produk secara bersamaan setiap empat hari.

e. Perbandingan Total Biaya Kekurangan Kondisi Saat ini dan Usulan

f. Pada kondisi saat ini, tidak terdapat biaya kekurangan. Sedangkan pada kondisi usulan total biaya kekurangan sebesar Rp109,744,747. Hal ini dikarenakan biaya kekurangan yang dimaksud adalah kemungkinan terjadinya lost sales.

g. Analisis Perbandingan Total Biaya Persediaan

h. Berdasarkan hasil yang diperoleh bahwa terdapat penurunan biaya persediaan di PT.XYZ sebesar Rp473,495,683 atau 45.80\%. Hasil ini menunjukkan bahwa dengan menggunakan metode Joint replenishment dan model P, PT.XYZ dapat meminimasi total biaya persediaan. Hal ini dikarenakan jumlah persediaan dan interval waktu pemesanan sudah diatur sesuai dengan demand, jumlah maksimum inventory level dan safety stock pada kondisi saat ini.

\section{KESIMPULAN}

Sesuai dengan tujuan penelitian, kebijakan persediaan dapat diperoleh dengan parameter yang dihasilkan berupa interval review, reorder point, jumlah maksimum inventori, safety stock, serta penghematan terhadap total ongkos persediaan usulan melalui metode Joint replenishment dan model P. Kebijakan persediaan usulan beberapa produk yang diperoleh dari perhitungan pada penelitian ini dapat dilihat pada Tabel VII. Pada perhitungan menggunakan metode Joint replenishment, interval antar pemesanan diperoleh sebesar 0.155 bulan atau sekitar 4 hari. Sebagai contoh pada SKU Z21KIA481HETA2E1, pemesanan kembali atau reorder point yang didapat adalah 4 hari. Maka dari itu, pemesanan dilakukan jika pada saat itu posisi inventori kurang dari maksimum inventori level. Jumlah maksimum inventori level untuk SKU Z21KIA481HETA2E1 yaitu sebesar 37120 unit, sehingga pemesanan dilakukan jika barang di gudang kurang dari 37120 unit. Cadangan pengaman pada SKU Z21KIA481HETA2E1 yaitu 8312 unit. Jumlah ini dapat digunakan jika permintaan sewaktuwaktu berubah. Kebijakan Persediaan tersebut mempengaruhi total biaya persediaan PT XYZ. Berikut Tabel VIII merupakan perbandingan total biaya persediaan terhadap kondisi saat ini dan usulan.

TABEL VII

KEBIJAKAN PERSEDIAAN USULAN

\begin{tabular}{ccccc}
\hline SKU & $\begin{array}{c}\text { Interval } \\
\text { review } \\
(\mathrm{T})\end{array}$ & $\begin{array}{c}\text { ROP } \\
\text { (hari) }\end{array}$ & $\begin{array}{c}\text { Maksimum } \\
\text { Inventory } \\
\text { level }\end{array}$ & $\begin{array}{c}\text { Safety } \\
\text { stock }\end{array}$ \\
\hline Z21KIA481HETA2E1 & & 4 & 37120 & 8312 \\
Z21KAA481STBE2D1 & & 4 & 22119 & 6048 \\
Z21KIA481HEBE2E1 & $\mathbf{0 . 1 5 5}$ & 4 & 21643 & 5340 \\
Z21KAA481BOCR2A1 & & 8 & 300 & 88 \\
Z21KAA481LIGN6C1 & & 8 & 277 & 89 \\
\hline
\end{tabular}


TABEL VIII

PERBANDINGANTOTAL BIAYA

\begin{tabular}{crrrrr}
\hline & \multicolumn{2}{c}{ Saat ini } & \multicolumn{2}{c}{ Usulan } & Penghematan \\
\hline Os & $\mathrm{Rp}$ & 1.024 .744 .692 & $\mathrm{Rp}$ & 422.064 .917 & \multicolumn{1}{c}{$58,81 \%$} \\
$\mathrm{Op}$ & $\mathrm{Rp}$ & 8.976 .588 & $\mathrm{Rp}$ & 28.415 .932 & $0 \%$ \\
$\mathrm{Ok}$ & $\mathrm{Rp}$ & - & $\mathrm{Rp}$ & 109.744 .747 & $0 \%$ \\
Total & $\mathrm{Rp}$ & 1.033 .721 .280 & $\mathrm{Rp}$ & 560.225 .597 & \multicolumn{1}{c}{$45,80 \%$} \\
\hline
\end{tabular}

\section{DAFTAR PUSTAKA}

[1] B. P. Statistik, "Badan Pusat Statistik," 16 November 2016. [Online]. Available: https://www.bps.go.id/.

[2] M. K. Starr and D. W. Miller, Inventory control: theory and practice, Englewood Cliffs, N.J., Prentice-Hall, 1962.

[3] C. M. Rao and K. P. Rao, "Inventory Turnover Ratio as a Supply Chain," Serbian Journal of Management 4, vol. 4, pp. 41-50, 2009.

[4] T. I. Rahmadika, D. D. Damayanti and B. Santosa, "Penentuan Kebijakan Persediaan Darah di Bank Darah Rumah Sakit XYZ Menggunakan Metode Joint Replenishment untuk Meningkatkan Service Level," in $e$ Proceeding Telkom University, Bandung, 2016.

[5] S. K. Goyal, "Determination of optimum packaging frequency of items joint replenished," Management Science 21, vol. 21, pp. 436-443, 1974.

[6] M. K. Salamesh, A. A. Yassine, B. Maddah and L. Ghaddar, "Joint replenishment model with substituion," Apllied Mathematical Modelling , vol. 38, pp. 3662-3671 , 2014.

[7] S. K. Goyal and A. T. Satir, "Joint replenishment inventory control Deterministic and stochastic models," European Journal of operational Research, vol. 38, pp. 2-13, 1989.

[8] P. Wanke, "Production and Inventory Management Journal," Production and Inventory Management Journal, vol. 49 No.1, 2014.

[9] S. N. Bahagia, Sistem Inventori, Bandung: Institut Teknologi Bandung, 2006.

[10] A. Eynan and D. H. Kropp, "Effective and simple EOQlike solutions for stochastic," European Journal of Operational Research 180, p. 1135-1143, 2007.

[11] A. Eynan and D. H. Kropp, "Periodic Review and Joint Replenishment in stochastic demand environment," IIE Transactions, vol. 30, pp. 1025-1033, 1998. 